\title{
Villous Projections of the Neoplastic Epithelium Present
}

National Cancer Institute

\section{Source}

National Cancer Institute. Villous Projections of the Neoplastic Epithelium Present. NCI

Thesaurus. Code C96467.

A morphologic finding indicating the presence of prominent, thin, elong ated projections

of the neoplastic glandular epithelium in the colorectal mucosa. 